\title{
Nutritional status and associated factors among adult HIVIAIDS clients in Felege Hiwot Referral Hospital, Bahir Dar, Ethiopia
}

\author{
Molla Daniel ${ }^{1}$, Fekadu Mazengia ${ }^{2}$, Dereje Birhanu ${ }^{3, *}$ \\ ${ }^{1}$ Amhara National Regional State Health Bureau, Nutrition officer, Bahir Dar, Ethiopia \\ ${ }^{2}$ University of Gondar, College of Medicine and Health Sciences, Department of Public Health, Gondar, Ethiopia \\ ${ }^{3}$ Bahir Dar University: College of Medicine and Health Science, Department of Public Health; Bahir Dar, Ethiopia \\ Email address: \\ molla_danie196@yahoo.com (M. Daniel), mazengiafek23@gmail.com (F. Mazengia), firedereje@gmail.com (D. Birhanu)
}

To cite this article:

Molla Daniel, Fekadu Mazengia, Dereje Birhanu. Nutritional Status and Associated Factors Among Adult HIV/AIDS Clients in Felege Hiwot Referral Hospital, Bahir Dar, Ethiopia. Science Journal of Public Health. Vol. 1, No. 1, 2013, pp. 24-31.

doi: $10.11648 /$ j.sjph.20130101.14

\begin{abstract}
Background: HIV/AIDS and malnutrition effects are interrelated and exacerbate one another in a vicious cycle. HIV specifically affects nutritional status by increasing energy requirements, reducing food intake, and adversely affecting nutrient absorption and metabolism. In Ethiopia since its detection, has claimed lives of millions. Even in the era of ART, it could not be tackled since the dispute of malnutrition is unanswered. Therefore the study aimed to assess nutritional status and associated risk factors among adult HIV/AIDS clients in Bahir Dar, Ethiopia. Method: was facility based cross sectional survey in Felege Hiwot referral Hospital. On average 50-60 Pre-ART and/or on ART care clients were visiting the Hospital daily. Taking the first patient as case one, every $4^{\text {th }}$ of daily attendances were interviewed using interviewer administered questionnaire and anthropometric measurements. SPSS version 16 statistical software was used to enter and analyze the data. Binary logistic regression was used to assess effect of factors on HIV/AIDS clients' nutritional status. P value $\leq 0.05$ was considered statistical significant. Results: 408 HIV/AIDS clients were interviewed, of them 104 (25.5\%) were chronic energy deficient (BMI $<18.5 \mathrm{~kg} / \mathrm{m} 2) ; 36.5 \%$ from pre-ART, $63.5 \%$ from on ART care. Proportion of mildly, moderately, and severely malnourished participants were $64.4 \%, 19.2 \%$, and 16.4\% respectively. Females were most affected (56.7\%). HIV/AIDS related symptoms 2 weeks prior to the survey $(\mathrm{AOR}=1.93,95 \% \mathrm{CL}: 1.18-10.0)$; eating difficulty $(\mathrm{AOR}=1.80,95 \% \mathrm{CL}$ : 1.10-2.04); Pre ART clients (AOR=1.77, 95\% CL: 1.08-2.90); and on ARV drugs < 12months (AOR=1.7, 95\% CL: 1.04-3.78) were the predictors associated to malnutrition. Conclusions: Chronic energy deficiency was prevalent in PLWHA. HIV related symptoms, feeding difficulties and duration on ART were the predictors for malnutrition. Only increasing access to ART can't solve problem of malnutrition, therefore nutrition therapy and support as an adjunct to the initiation of ART should be considered.
\end{abstract}

Keywords: Malnutrition, Nutritional Status, HIV, Antiretroviral Therapy

\section{Introduction}

Back ground: - More than 33.2 million people are living with HIV throughout the world. The greatest burden of the disease is concentrated in developing countries, the least able to cope. In these regions, HIV/AIDS has deepened poverty and exacerbated food insecurity $[1,2]$.

HIV/AIDS and malnutrition effects are interrelated and exacerbate one another in a vicious cycle. HIV specifically affects nutritional status by increasing energy requirements, reducing food intake, and adversely affecting nutrient absorption and metabolism. Asymptomatic and symptomatic adults have energy requirements by $10 \%$ and $30 \%$ respectively to maintain body weight and physical activity [3-5].

Evidence has shown that adequate nutrition for a person living HIV (PLHIV) is necessary to maintain and improve the overall health and nutritional status. Promising developments have been seen in recent years in global efforts to address AIDS epidemic by increasing the access to effective treatment and prevention programmes. Globally, the number of people accessing ART has been increasing; as a result more people living HIV are leading healthier and productive life [6-7].

ARV treatment and good nutrition are important parts of 
preventing opportunistic infections like tuberculosis and pneumonia, which are considered the hallmarks of AIDS patients $[11,12]$. Ethiopia is one of the countries hit hardest by HIV epidemic alongside of malnutrition and it occurs in severe forms and affects many people either before or within the era of ART [14-16]. There is little evidence in Ethiopian context in general and in the study area in particular regarding to the nutritional condition of peoples' living HIV/AIDS whether they are in pre ART or ART care. Therefore the purpose of this study aimed to assess the nutritional status and associated risk factors for malnutrition of adult HIV/AIDS clients in pre-ART and on ART care in Felege Hiwot Referral Hospital, Bahir Dar, Ethiopia.

\section{Methodology}

\subsection{Study Design and Period}

Facility based cross-sectional study was conducted from 16 Sept. to 16 Oct 2009.

\subsection{Study Area and Setting}

The study was carried out at Felege Hiwot Referral Hospital in Bahr Dar Ethiopia, the capital city of Amhara Regional State situated $565 \mathrm{Km}$ Northwest of Addis Ababa. It was the only Hospital in the town. The Hospital was built in 1983 to serve about 25,000 people but now it is serving more than 5 million people. A total of 9024 adult HIV/AIDS patients have been enrolled to HIV/AIDS chronic care in Felege Hiwot Referral Hospital, of which 2443 were in pre-ART care, and 6581 were on ART care.

\subsection{Source and Study Population}

The source populations were the total cohort of HIV/AIDS patients who were enrolled to ART care clinic in Felege Hiwot referral Hospital and the study populations were people aged 18 years and older who were actively taking ARV drugs, and/or those who followed HIV/AIDS chronic care but not yet started ART.

\subsection{Inclusion and Exclusion Criteria}

Those who were actively following HIV/AIDS chronic care in Felege Hiwot Referral Hospital and aged 18years and older were included in the study while patients who were seriously ill and/or with spinal deformity were excluded.

\subsection{Sampling Size Determination and Sampling Proce- dure:- Sample Size Determination}

The required sample size was determined using single population proportion formula $n=\left(z^{2} * P(1-P) / d^{2}\right)$, where $n$ is the sample size, $\mathrm{z}$ is the standard normal score set at 1.96 , $\mathrm{d}$ is the desired degree of accuracy and $\mathrm{p}$ is the estimated proportion of the target population. By taking $\mathrm{p}=40 \%$ (proportion of malnourished people living HIV/AIDS) [22], $\mathrm{z}=1.96$ and $\mathrm{w}=5 \%$, the computed sample size was 369 and by taking $10.5 \%$ non response rate, the total sample size computed was 408 .

\subsection{Sampling Procedure}

From the total $9020 \mathrm{HIV} /$ AIDS patients who were in pre-ART and on ART chronic care, 6581 were on ART and 2443 were on Pre-ART care. Therefore in order to select 408 participants from on ART and Pre-ART cases proportionately, we used mathematical equation. That means $\mathrm{n} 1=$ $(\mathrm{N} 1 * \mathrm{nf}) / \mathrm{Nt}$. At the same time, $\mathrm{n} 2=(\mathrm{N} 2 / \mathrm{nf}) / \mathrm{Nt}$, where $\mathrm{n} 1$ was the required sample size from ART care cases, $\mathrm{n} 2$ was the required sample size from Pre-ART care cases, nf was the total required sample size, N1was the total number of ART care cases, N2 was the total number of pre-ART care cases, and $\mathrm{Nt}$ was the total number of both on ART and on Pre-ART care cases. I.e., $\mathrm{n} 1=(6581 * 408) / 9020=298$, and $\mathrm{n} 2=(2443 * 408) / 9020=110$ cases were selected proportionately. Since $n f=n 1+n 2$, then a total of 298 cases from on ART care, and a total of 110 cases from Pre-ART care were recruited making the final sample size 408. According to the Hospital report, on average 50-60 Pre-ART and on ART clients were visiting the Hospital daily. Using the office hours and taking the first client as case one, every fourth of the daily attended during the data collection period were included and interviewed.

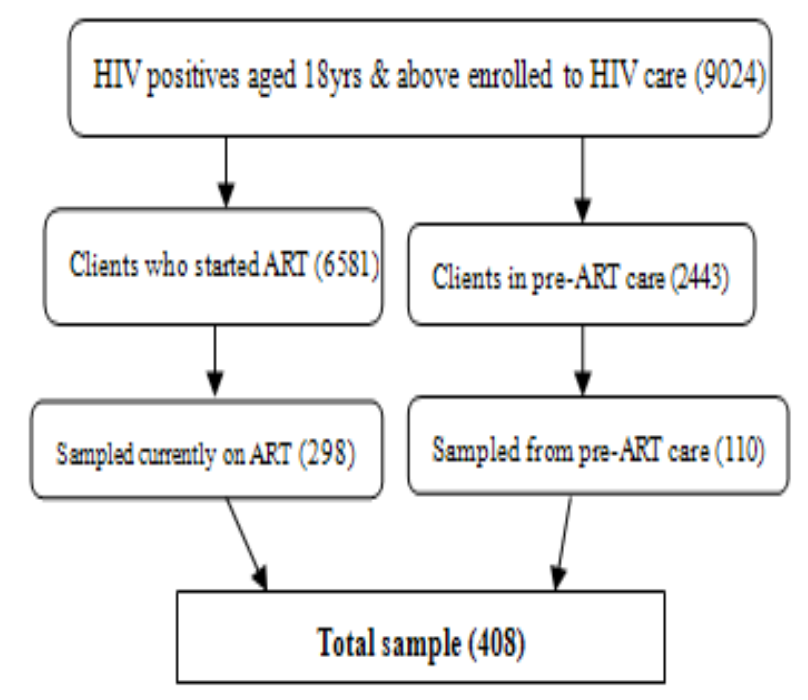

Fig. 1. Thematic presentation participant selection.

\subsection{Data Collection Tool and Procedure}

The data was collected from 16 Sept -16 Oct 2009 using semi structured interviewer administered questionnaire. Three data collectors (two ART adherence counselors, and one HIV/AIDS nurse specialist) and one supervisor were recruited and two days training was given. The data collection process was followed daily by the supervisor and principal investigators.

Weight of participants was taken using standard beam balance and the scale was checked at zero before and after each measurement. Participants' weight was measured after removing heavy clothes and was recorded to the nearest 
$0.1 \mathrm{KG}$.

Height measurement of participants was taken using the standard measuring scale. Participants' takeoff their shoes, stand erect, and look straight in horizontal plain. The occipit, shoulder, buttocks, and heels touched measuring board and height was recorded to the nearest $0.01 \mathrm{~cm}$.

\subsection{Data Quality Issues}

The questionnaire was adapted and modified in to our context from previous literatures. It was prepared first in English and then translated into the local language Amharic, and then retranslated back to English by an expert who was fluent in both languages to maintain its consistency. Training was given for data collectors and supervisor. Pre testing of the questionnaire was made on 20 pre-ART and/or on ART care clients in the nearby Health Center a week prior to the actual survey. Data collection process was strictly followed day to day by the supervisor and principal investigators.

\subsection{Data Processing and Analysis}

Questionnaires were checked for completeness, coded, and entered into SPSS version 16 statistical package. Logistic regressions analysis was computed to assess the associations of the various factors against the level of malnutrition. Variables with a p-value of less than 0.2 in the bivariate analysis were entered into the final model. $\mathrm{P}$ value $\leq 0.05$ at $95 \%$ CI was considered statistically significant. Strength of association between predictor and outcome variables was assessed using odds ratio.

\subsection{Ethical Considerations}

Prior to data collection, ethical approval was obtained from ethical review committee of University of Gondar, College of Medicine and Health Sciences, Department of Public Health. Permission was obtained from Amhara Regional Health Bureau and from Felege Hiwot Referral Hospital administrators. Verbal consent was taken from each participant after the purpose of the study was explained. They were told to withdraw at any time and/or to refrain from responding to questions they were not interested to respond. Participants were also informed that all the data obtained from them would be kept confidential using codes instead of any personal identifiers.

\section{Result}

\subsection{Socio-Demography Characteristics of Respondents}

A total of 408 HIV/AIDS clients responded to the questionnaire making the response rate $100 \%$. Females accounted 243(59.6\%), the majority $375(92 \%)$ were orthodox Christian and 384 (94.1\%) from Amhara ethnic group. Most were urban dwellers 380(93.1\%); and nearly half of the respondents (45.6\%), monthly income range 151- 650 ETB (Table 1).
Table 1. Socio demographic characteristics of respondents at Felege Hiwot Hospital, Bahir Dar, Ethiopia, 2009

\begin{tabular}{|c|c|c|}
\hline Variables $(n=408)$ & Frequency & Percent \\
\hline \multicolumn{3}{|l|}{ Age of respondents } \\
\hline $18-29$ & 122 & 29.9 \\
\hline $30-44$ & 230 & 56.4 \\
\hline$\geq 45$ & 56 & 13.7 \\
\hline \multicolumn{3}{|l|}{ Sex } \\
\hline Male & 165 & 40.4 \\
\hline Female & 243 & 59.6 \\
\hline \multicolumn{3}{|l|}{ Marital status } \\
\hline Unmarried & 49 & 12.0 \\
\hline Married & 219 & 53.7 \\
\hline Divorced & 65 & 15.9 \\
\hline Separated & 35 & 8.6 \\
\hline Widowed & 40 & 9.8 \\
\hline \multicolumn{3}{|l|}{ Religion } \\
\hline Orthodox & 375 & 91.9 \\
\hline Others* & 33 & 8.1 \\
\hline \multicolumn{3}{|l|}{ Residence } \\
\hline Urban & 380 & 93.1 \\
\hline Rural & 28 & 6.9 \\
\hline \multicolumn{3}{|l|}{ Ethnic group } \\
\hline Amhara & 384 & 94.1 \\
\hline Others $* *$ & 24 & 5.9 \\
\hline \multicolumn{3}{|l|}{ Educational status } \\
\hline$\leq$ Grade 4 & 144 & 35.0 \\
\hline Grade 5-8 & 91 & 22.0 \\
\hline Grade $9 \&$ above & 173 & 43.0 \\
\hline \multicolumn{3}{|l|}{ Occupation } \\
\hline Gov’t employed & 106 & 26.0 \\
\hline Daily laborer & 88 & 21.6 \\
\hline Self employed & 66 & 16.2 \\
\hline House wife & 61 & 15.0 \\
\hline Merchant & 58 & 14.2 \\
\hline Others & 29 & 7.0 \\
\hline \multicolumn{3}{|c|}{ Monthly income in Eth Birr (1US Dollar $=18.50$ Eth Birr) } \\
\hline$\leq 150$ & 92 & 22.5 \\
\hline $151-650$ & 186 & 45.6 \\
\hline $651-1400$ & 65 & 16.0 \\
\hline$\geq 1400$ & 65 & 16.0 \\
\hline
\end{tabular}

Regarding to the nutrition and HIV/AIDS related characteristics of participants; more than $2 / 3^{\text {rd }}$ were in clinical stage III. One third had $\mathrm{CD}_{4}$ count $<200$ cells $/ \mu \mathrm{L}$, were complaining eating difficulty. More than $90 \%$ were counseled on dietary issues but more than $80 \%$ didn't have nutritional support (Table 2). 
Table 2. Nutritional status and socio demographic characteristics of adult HIV/AIDS clients in Felege Hiwot Referral Hospital, 16 Sept-16 Oct 2009, Bahir Dar Ethiopia

\begin{tabular}{|c|c|c|}
\hline Variables/ Response & Frequency & Percent \\
\hline \multicolumn{3}{|c|}{ HIV related symptoms $(n=408)$} \\
\hline Yes & 120 & 29.4 \\
\hline NO & 288 & 70.6 \\
\hline \multicolumn{3}{|l|}{ Clinical stage $(n=408)$} \\
\hline Stage I & 45 & 11.0 \\
\hline Stage II & 61 & 15.0 \\
\hline Stage III & 269 & 65.9 \\
\hline Stage IV & 33 & 8.1 \\
\hline \multicolumn{3}{|l|}{ CD4 $\operatorname{count}(n=408)$} \\
\hline$<200$ & 137 & 33.6 \\
\hline $200-500$ & 208 & 51.0 \\
\hline$>500$ & 63 & 15.4 \\
\hline \multicolumn{3}{|l|}{ Eating difficulty (n=112) } \\
\hline Loss of appetite & 42 & 37.5 \\
\hline Appetite loss/vomiting & 23 & 20.5 \\
\hline Vomiting & 19 & 16.9 \\
\hline Swallowing difficulty & 16 & 14.5 \\
\hline Others & 12 & 10.7 \\
\hline \multicolumn{3}{|l|}{ Dietary counseling $(n=408)$} \\
\hline Yes & 381 & 93.0 \\
\hline No & 27 & 7.0 \\
\hline \multicolumn{3}{|c|}{ Change feeding style after knowing HIV status $(\mathbf{n}=\mathbf{3 1 7})$} \\
\hline Quality food & 136 & 43.0 \\
\hline Frequency & 101 & 32.0 \\
\hline Feeding cooked food & 74 & 23.2 \\
\hline Others & 6 & 1.8 \\
\hline \multicolumn{3}{|l|}{ Nutritional support $(n=408)$} \\
\hline Yes & 74 & 18.1 \\
\hline No & 334 & 81.9 \\
\hline \multicolumn{3}{|c|}{ Disclosure their status(n=408) } \\
\hline Yes & 390 & 95.6 \\
\hline No & 18 & 4.4 \\
\hline
\end{tabular}

Regarding to respondent's nutritional status, the mean BMI was $20.5 \mathrm{~kg} / \mathrm{m}^{2} \pm 2.9$. The proportion of chronic energy deficiency $(\mathrm{BMI}<18.5 \mathrm{Kg} / \mathrm{m} 2)$ was found $25.5 \%$. From the total participants, the age group 30-44 years accounted 230 (56.4\%) and the age group 18-29 accounted 29.9\%. From the total 104 malnourished, the age group 30-44 were the most affected, $60(57.7 \%)$ followed by the age group 18-29 years $31(28.8 \%)$. Considering sex, from the total 408 participants, females were $59.9 \%$. From the total 243 female participants $59(23.0 \%)$ and from the total 165 male participants, $45(27.3 \%)$ were malnourished, but from the total 104 malnourished, females were more affected than males $(56.7 \%$ vs. $43.3 \%)$ respectively. Considering participants residence, from the total 408 who participated in the study, $380(93.1 \%)$ were urban residents and from them 99 (26.1\%) were malnourished but from the total 104 malnourished, 99 (95.2\%) were urban residents. From the total 408 study participants, nearly half $186(45.6 \%)$ were with an average income of 151-650 Ethiopian Birr, and from them 45(24.2\%) were malnourished. From the total 408 participants, 92 $(22.5 \%)$ were with an average monthly income of $\leq 150$ Eth. Birr, and from them 29(31.5\%) were malnourished. More than two third of the malnourished were with an average monthly income of $\leq 650$ Ethiopian Birr (Table 3).

Table 3. Nutritional status and socio demographic characteristics of adult HIV/AIDS clients in Felege Hiwot Referral Hospital, 16 Sept-16 Oct 2009, Bahir Dar Ethiopia

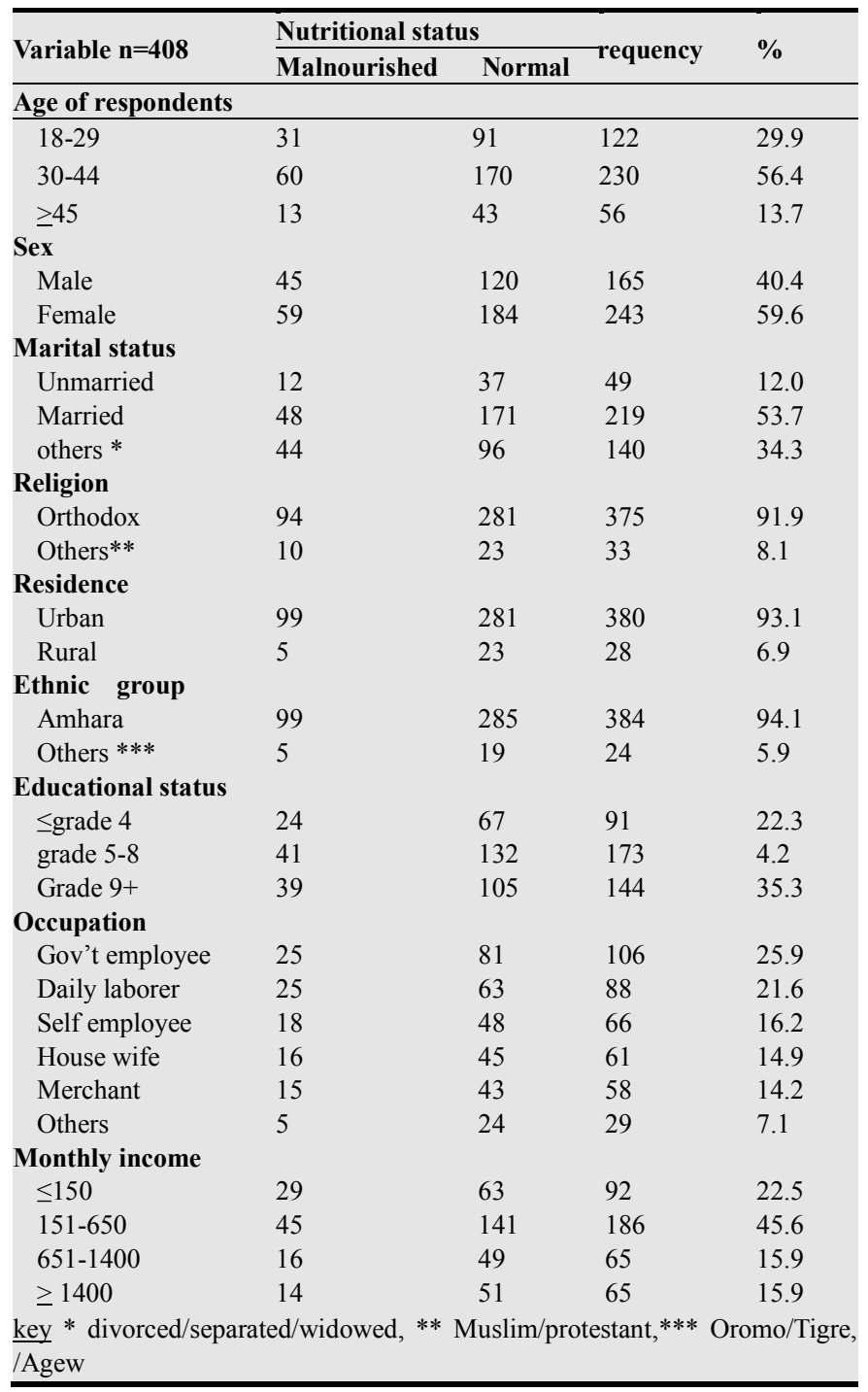

From the total $104(25.5 \%)$ malnourished, 38 (36.5\%) \& $66(63.5 \%)$ were those from pre-ART and on ART care respectively and the Proportion of mildly (BMI17.0-18.4kg/m²), moderately $\left(16.0 \mathrm{~kg} / \mathrm{m}^{2}-16.9 \mathrm{~kg} / \mathrm{m}^{2}\right.$ and severely $\left(\mathrm{BMI}<16.0 \mathrm{~kg} / \mathrm{m}^{2}\right)$ malnourished clients were $67(64.4 \%), 20(19.2 \%)$ and $17(16.4 \%)$ respectively.

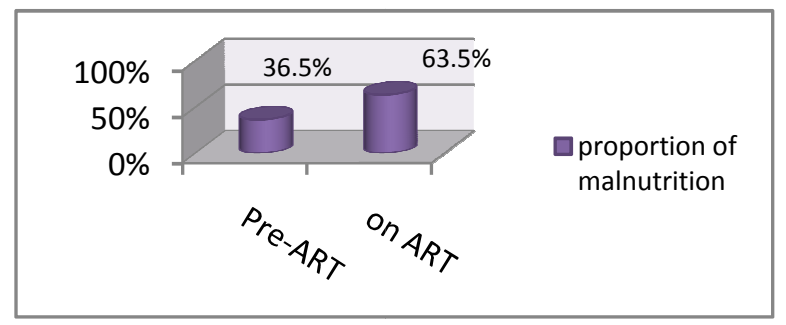

Figure 2. proportion of malnutrition among pre-ART and on ART adult HIV/AIDS patients in Felege Hiwot Referral Hospital, Bahir Dar Ethiopia Sept 16 to Oct 162009 
Descriptively those who were in Pre-ART care were moderately and severely malnourished more than those who were on ART care but most of the participants who were on
ART care were mildly malnourished more than those who were in Pre-ART care but were not statistically significant.

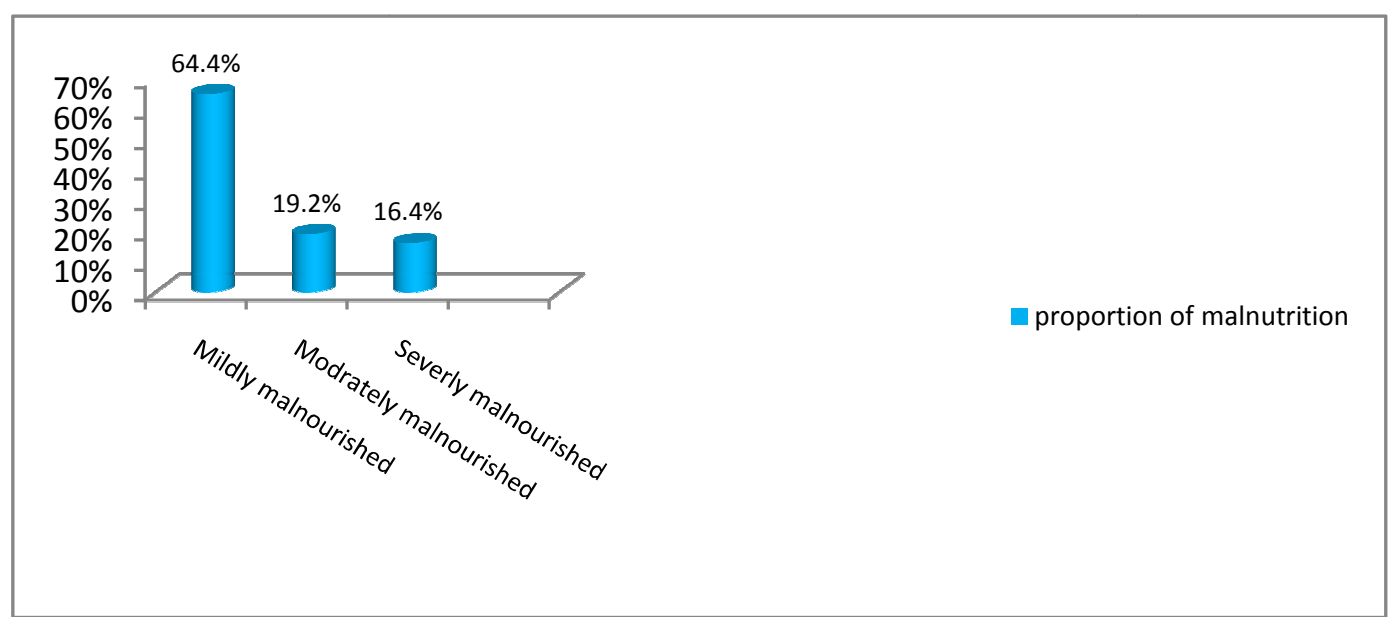

Figure 3. percentage of severity of malnutrition among adult clients in Pre ART and on ART, Felege Hiwot Referral Hospital, Bahir Dar 16 Sept to 16 Oct 2009

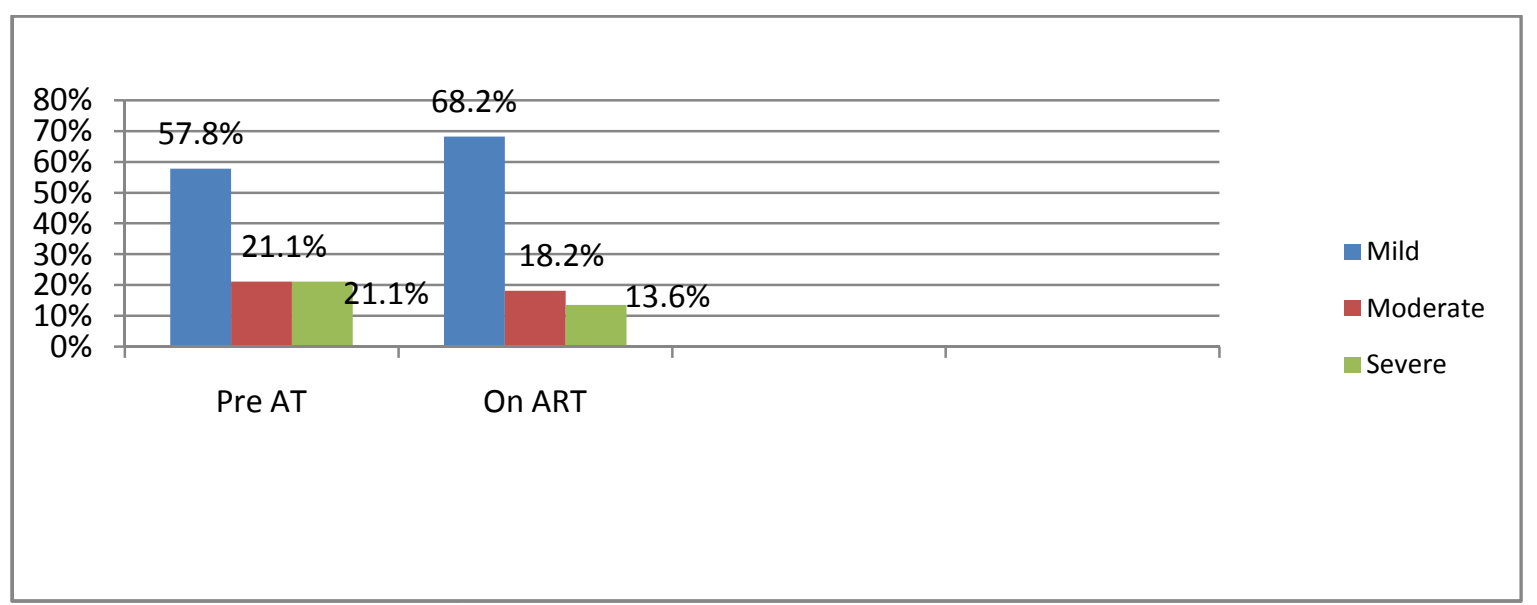

Figure 4. Proportion of malnutrition in adult HIV/AIDS chronic care among Pre-ART and on ART at Felege Hiwot Referral Hospital Bahir Dar, Ethiopia, from 16 Sept. to 16 Oct. 2009.

From the total malnourished, females were more affected than males ( $56.7 \%$ vs. $43.3 \%$ ), even from pre-ART malnourished clients, more than $2 / 3^{\text {rd }}(71 \%)$ were females, but the proportion of malnutrition among on ART care clients was relatively comparable between Females (48\%) and Males $(52 \%)$.

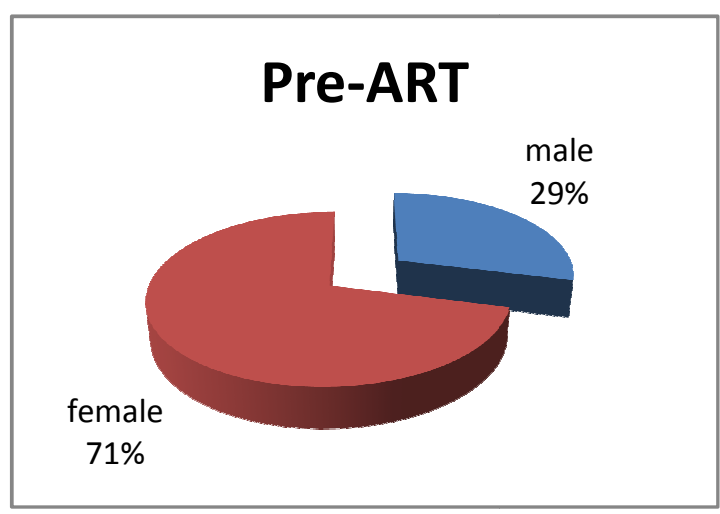

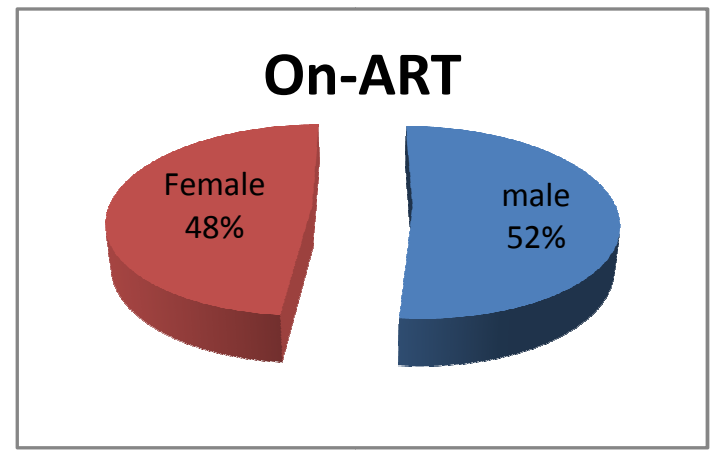

Figure 5. Nutritional status of chronic HIV/AIDS care clients considering sex of respondents at Felege Hiwot Referral Hospital, Bahir Dar, Ethiopia from 16 Sept to 16 Oct 2009

Factors affecting the nutritional status of HIV/AIDS clients who were in pre-ART and on ART care were assessed using binary logistic regression. The analysis showed that HIV related symptoms within two weeks prior to data collection; feeding difficulty, ART status, and duration on ART 
were found to have significant association on nutritional status of HIV/AIDS clients who were on chronic care. Odds ratio with their corresponding $95 \%$ confidence level were summarized in table 4 below.

Table 4. Associated risk factors for malnutrition in HIV/AIDS clients in pre-ART and on ART care in Felege Hiwot Referral Hospital, 16 Sept to 16 Oct 2009, Bahir Dar Ethiopia. Variable/ Response

\begin{tabular}{|c|c|c|c|c|}
\hline & \multicolumn{2}{|c|}{ Nutritional status } & \multicolumn{2}{|l|}{$95 \% \mathrm{CI}$} \\
\hline & Malnourish & Normal & COR & AOR \\
\hline \multicolumn{5}{|l|}{ Sex } \\
\hline Female & 59 & 184 & $0.86(0.55-1.34)$ & $0.54(0.52-0.95)^{* *}$ \\
\hline Male & 45 & 120 & 1 & 1 \\
\hline \multicolumn{5}{|c|}{ Monthly income in ETB } \\
\hline$\leq 150$ & 29 & 63 & $1.48(0.94-7.46)$ & $1.74(0.98-11.0)$ \\
\hline$\square 150$ & 75 & 241 & 1 & 1 \\
\hline \multicolumn{5}{|c|}{ Symptoms 2 wks prior to survey } \\
\hline Yes & 41 & 79 & $.85(1.16-2.96) *$ & $1.93(1.18-10.0)^{* *}$ \\
\hline No & 63 & 225 & 1 & 1 \\
\hline \multicolumn{5}{|l|}{ Eating difficulty } \\
\hline Yes & 37 & 73 & $97(1.08-2.82) *$ & $1.80(1.10-2.04) * *$ \\
\hline No & 67 & 261 & 1 & 1 \\
\hline \multicolumn{5}{|l|}{ ART status } \\
\hline Pre-ART & 38 & 72 & $1.86(1.16-3.0) *$ & $1.77(1.08-2.90) * *$ \\
\hline ART & 66 & 232 & 1 & 1 \\
\hline \multicolumn{5}{|l|}{ ART duration } \\
\hline$\leq 12$ month & 20 & 44 & $1.86(1.0-3.45) *$ & $1.70(1.04-3.78) * *$ \\
\hline$>12$ months & 46 & 188 & 1 & 1 \\
\hline \multicolumn{5}{|l|}{ Current CD4 count } \\
\hline$>200$ & 62 & 209 & $0.67(0.42-1.06)$ & $0.67(0.42-1.08)$ \\
\hline$\leq 200$ & 42 & 95 & 1 & 1 \\
\hline
\end{tabular}

\section{Discussion}

Malnutrition and HIV/AIDS effects are interrelated and exacerbate one another in a vicious cycle. Both HIV/AIDS and malnutrition independently cause progressive damage to the immune system and increased susceptibility to infection. Since the introduction of ART, the prevalence of malnutrition has diminished but not yet disappeared. In this study the prevalence of malnutrition in HIV/AIDS clients who attend chronic care was $25.5 \%$. The prevalence was much lower than a study done in India (72\%) [17], Malawi (57\%) [18] But is higher than a study done in Boston (18\%) [19], SSA (10.3\%) [20], Lusaka Zambia (15.8\%) [21], and in Addis Ababa 18\% [22]. The difference may be due to residence, socio culture, economic and/or year of study.

The prevalence of malnutrition varied based on client's ART status (pre-ART and on ART). In this study, the prevalence of malnutrition was higher in pre ART (34.5\%) than on ART $(21.1 \%)$ clients. The pre-ART finding is in agreement with $[22,23,24]$, but the proportion of malnutrition among on ART care clients was higher than other studies [22, 23, 24]; the difference may possibly be due to poor adherence to ART and/or to the counseling services.

Malnutrition could occur in different forms and degrees. When we consider the degree of malnutrition, it varies in different settings and circumstance. In our study for example, from the total malnourished; $64.4 \%, 19.2 \%$, and $16.4 \%$ were in mild, moderate and severe malnutrition respectively. In other studies the proportion of the degree of malnutrition was $27 \%$ mildly, $31 \%$ moderately and $42 \%$ severely [17]; $22 \%$ mildly, $14 \%$ moderately, and $21 \%$ severely [18]; $31.7 \%$ mildly, $25.9 \%$ moderately and $42.4 \%$ were severely malnourished [25]. From the above descriptive results, we looked differences in the distribution of degree of malnutrition. What so ever the difference in degree of malnutrition is; what clearly seen is HIV/AIDS related malnutrition is the major problem to HIV/AIDS patients.

Descriptively, from the total participants, females accounted about $60 \%$, and from whom 59 (24.3\%) were malnourished. Males accounted 40\%, of them 45 (27.3\%) were malnourished. From the total malnourished, the proportion of malnutrition was much higher in females who were on Pre-ART care (71\%) than males $(29 \%)$, as compared to the relatively similar proportion of malnutrition among females and males who were on ART care i.e. females (52\%) vs. males (48\%). Females were more malnourished than males in those who were on Pre-ART care, may be possibly at this stage; females might consider themselves healthy so more of the attention would be given to their children and/or to their family than taking care to themselves and to consume better food sources to maintain their nutrition. But proportion of female malnutrition in ART care was almost similar to males possibly may be due to their commitment to adhere to ARV treatment, and/or to the counseling given. Logistic regression analysis result showed the strong association between sex and level of malnutrition where being female was $46 \%$ less likely to be malnourished than males, $\mathrm{AOR}=\mathbf{0 . 5 4}, \mathbf{9 5 \%} \mathrm{CL}(\mathbf{0 . 5 2}-\mathbf{0 . 9 5})$. Possibly she might get committed to adhere to ARV treatment, and/or to the counseling given and she might also get committed to consume balanced diet in order to lengthen her life not only for herself but for the sake of her children and to her family than what males could did, because in our society, females 
are the most responsible to prepare, feed, and care for the whole family. In addition in our society, factors that could lead to malnutrition such as alcohol consumption, cigarette smoking, are not practiced by females as compared to males.

With regard to HIV/AIDS related symptoms, those who develop disease symptoms two weeks prior to the survey, were almost two times more malnourished than those who were free of symptoms, AOR=1.93, 95\% CL (1.18 - 10.0). Implying that, clients in chronic care should be strongly advised to take preventive actions and to seek medical care as soon as possible.

It is known that infection could affect nutritional status, either through loss of appetite, oral/throat sore, and/or due to other gastroenteritis problems. In this study clients who suffered from eating difficulties prior to the survey were nearly two times more malnourished than those who didn't have eating difficulty, $A O R=1.80,95 \%$ CL (1.10-2.04) implying that counselors should take action in educating what to do when clients are complaining difficulty of feeding so that preventive actions and early management of symptoms would be carried which could reduce occurrence of malnutrition.

From the total malnourished, those who were on pre- ART care were malnourished 1.5 times more than those who were on ART care, $A O R=1.77,95 \%$ CL (1.08 - 2.90), this could possibly be due to the fact that those who were on Pre-ART care may not give much attention on what to eat, how frequent to eat, what precaution to take regarding on feeding as they may consider themselves healthy as other community groups and also counselors may not tell them what to and not to do to pre-ART clients than those who were on ART care. But who were on ART were those enrolled to take ARV drugs as they were with low CD4 count, could improve their nutritional status as they may adhere better to ART treatment and to the counseling they were given by counselors. Therefore, counseling should focus to Pre-ART care clients as what is being done regularly to on ART care cases and possibly the enrollment criteria may need also be seen and revised so that problem of malnutrition could be better addressed and reduced.

In this study, those who were on ARV drugs less than 12 months were 1.7 times more malnourished than those who took the drug more than a year, AOR=1.7, 95\% CL (1.04 3.78), this showed that adherence to ARV treatment contentiously and consistently throughout the life of an individual would help to improve the nutritional status of individuals. Educational status, Occupation, WHO clinical stage, monthly income, and disclosure status didn't show any significant effect on clients' nutritional status.

\section{Limitation of the Study}

Cross-sectional design by its very nature can't establish cause and effect relationship. The survey didn't assess the degree of malnutrition using body weight loss calculated by reference to the usual body weight.

\section{Conclusion}

A quarter of participants were in chronic energy deficiency, of which nearly $2 / 3^{\text {rd }}$ of the malnourished were in mild malnutrition.

Sex of respondent, HIV related symptoms, ART status, duration of ART, and eating difficulty were the predictors to malnutrition.

Due attention should be given to the mildly malnourished cases because they think they are healthy

HIV related symptoms and eating difficulty should be prevented and treated as early as possible.

ARV treatment should be accompanied by nutrition support through governmental \& non-governmental organizations.

\section{Abbreviations}

AOR, Adjusted Odds ratio; AIDS, Acquired Immunodeficiency Syndrome; ANRS, Amhara National Regional state; ARV, Antiretroviral; ART, Antiretroviral Treatment; BMI, Body Mass Index; Center for Diseases Control; CSA, Central statistic Authority; FBO, Faith Based Organization; FMOH, Federal Minister of Health; HAART, Highly Active Antiretroviral Treatment; HBC, Home Based Care; HIV, Human Immunodeficiency Virus; NGO, Non Governmental Organization; OI, Opportunistic Infection; PLHIV, People Living HIV; PLWHA, People Living With HIV/AIDS; PMTCT, Prevention of Mother to Child Transmission; SPSS, Statistical Package for Social Studies; SSA, Sub Saharan Africa; UN, United Nation; WHO, World Health Organization;

\section{Competing interests}

The authors declare that we have no competing of interests.

\section{Authors' Contributions}

All authors (DB, MD, and FM) contributed to the design of the study, MD contributed to data collection and data entry. DB, MD and FM performed the data analysis. DB drafted the manuscript. All authors critically revised and approved the final manuscript.

\section{Acknowledgement}

We are highly indebted to Amhara Regional Health Bureau, Bahir Dar Ethiopia, for sponsoring this research project. We would like to extend our thanks to Felege Hiwot Referral Hospital Administrators for permitting us to conduct the study. We would also like to extend our appreciation to the study participants, supervisors and data collectors.

\section{References}

[1] UNAIDS and WHO Global summary of the AIDS epidemic. 
AIDS epidemic Update December 2007, pp1-214. Switzerland Geneva

[2] The United States President's Emergency Plan for AIDS Relief Report on Food and Nutrition for People Living with HIV/AIDS, 05, May, 2007.pp25-30

[3] Stephen D. WORLD AIDS DAY the role of nutrition in living with HIV/ AIDS.01-Dec-2008.pp 12-15

[4] Daniel J. Raiten, Steven G. and Stephen A. Nutritional considerations in Resource-limited settings Consultation on Nutrition \& HIV/AIDS in Africa: Evidence, lessons \& recommendations for action 10-13 April 2005.

[5] Bonnard, Tony C., Bruce C., Leslie E., Sandra R. and Caroline NUTRITION and HIV/AIDS: Evidence, Gaps, and Priority Actions Academy for Educational Development (AED) prepared by Ellen Piwoz of the Support for Analysis and Research in Africa (SARA) project with inputs from Patricia 2006.

[6] The International Bank for Reconstruction and Development/the World Bank. HIV/AIDS, nutrition, and food security: what we can do. A Synthesis of international guidance, 2007).

[7] UNAIDS Report. Millennium Development Goals, Six things you need to know about the AIDS response today. 2010).

[8] Rachael M. Duke University Positive Living: Nutritional Realities and Interventions for People Living with HIV. May 2008 .

[9] Emily W., MD and Rachel R. Malnutrition HIV in Site Knowledge Base Chapter University of California San Francisco, October 2006

[10] Asgeir J., Ezra N., Bernard J et al. Predictors of mortality in HIV-infected patients starting antiretroviral therapy. In Tanzania Ural hospital. 22 April 2008.

[11] Food and Nutrition, Technical, Assistance Project (FANTA). Food and Nutrition Implications of Antiretroviral Therapy (ART) in Kenya A Formative Assessment February 2005.pp45-46

[12] Dale Ames Kline, MS, RD, CNSC, LD. Prevalence and pattern of HIV-related malnutrition among women in sub-Saharan Africa HIV/AIDS. HIV/AIDS: Immune Function \& Nutrition, July 2008.pp3-5.

[13] Tang A., Jacobson DL, Spiegel man D et al. Increasing risk of $5 \%$ or greater unintentional weight loss in a cohort of HIV infected patients, 1995 to 2003.
[14] Daniel J. Raiten, Steven G. and Stephen A. Consultation on Nutrition and HIV/AIDS in Africa: Evidence, lessons and recommendations for action, April, 2005.pp35-36

[15] The International Bank for Reconstruction and development/World Bank Nutrition, and food Security: what we can do. A Synthesis of international guidance 2007:

[16] The Federal Democratic Republic of Ethiopia Ministry of Health National Nutrition and HIV/AIDS Implementation Reference Manual. Ministry of Health Sept. 2008.

[17] Sati B, Garg DK, Purohit SD, Rathore R, Haag A, Mora C; Prevalence of malnutrition among HIV infected individuals in Rajasthan, India. Jul: 2004 abstract no. MoPeB3267.

[18] R.Zacharia, M.P.Spiemann, A.D.Harries and F.M.L.salanponi moderate to sever malnutrition in a patient with tuberculosis is a risk factor associated with early death; National Tuberculosis control program of Malawi community health science unit private; 2002, page 65 ,

[19] Olalekan A Uthman. Prevalence and pattern of HIV-related malnutrition among women in sub-Saharan Africa: meta-analysis of demographic health surveys, July, 2008

[20] Mangili A, Murman DH, Zampini AM et al. Nutrition and HIV infection: review of weight loss and wasting in the era of highly active antiretroviral therapy from the nutrition for healthy living cohort. Clinical Infectious Diseases, 2006, 42: 836-842.

[21] Kelly, P.; Summerbell, C.; Ngwenya, B.; Mandanda, B.; Hosp, M.; Fuchs, D.; Wachter, H.; Luo, N. P.; Pobee, J.O.M.; Farthing, M.J.G.Systemic immune activation as a potential determinant of wasting in Zambians with HIV-related diarrhea. Qjm. 89(11):831-837, November 199625.

[22] MOH and HAPCO, Monthly HIV Care and ART Update, by site as end of December 9, 2008 pp-2

[23] WHO, Department of Nutrition for Health and Development, Nutritional considerations in the use of ART in resource-limited settings Consultation on Nutrition and HIV/AIDS in Africa: Evidence, lessons and recommendations for action Durban, South Africa 10-13 April 2005, World Health Organization 2005

[24] Scevola D, Barbarini G, Bottari G, et al. International Conference on AIDS, Prevalence, etiology and management of AIDS in malnutrition, Jun 1991, Abstract no.W.B.2169.

[25] ACF International Network, Hunger and HIV; Adult ART and nutritional support on ART sites Malawi June-September 2005. 